Correction to Metall. Trans. A, 1990, vol. 21A, pp. 205-12

Solidification and Microstructure Analysis of Rapidly Solidified Melt-Spun Al-Fe Alloys by M.G. Chu and D.A. Granger

\title{
Page 208:
}

Figures 5(a) and (b) should be as follows:

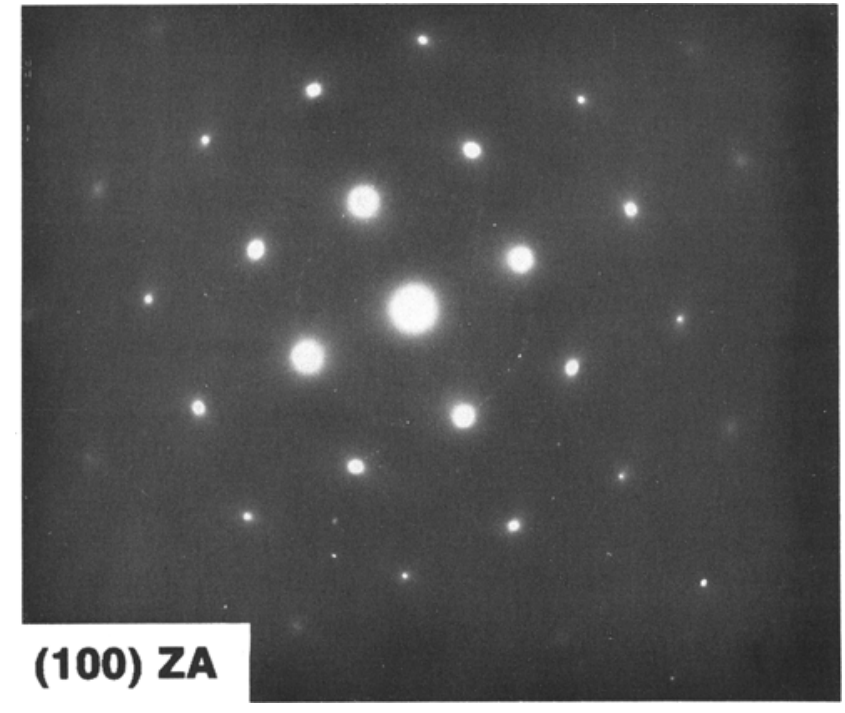

(a)

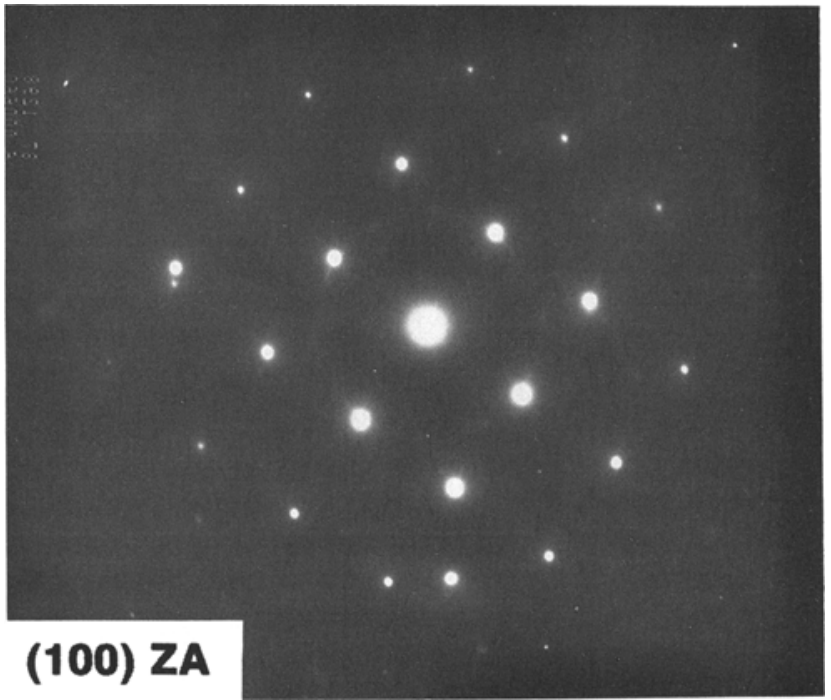

(b)

Fig. 5-Selected area diffraction pattern for microcellular region in (a) Al-2 wt pct Fe alloy and (b) Al-8 wt pct Fe alloy. 